\title{
INFLUENCE OF BETATIZATION HEAT TREATMENT ON MARTENSITIC TRANSFORMATION TEM- PERATURE OF INDUSTRIAL COPPER BASED SHAPE MEMORY ALLOYS
}

\author{
P. CHARBONNIER, L. BUFFARD, M. MORIN* and E. WEYNANT \\ IMAGO SA, Athélia 1, F-13600 LA Ciotat, France \\ *Institut National des Sciences Appliquées, GEMPPM, Bât 502, F-69621 Villeurbanne cedex, France
}

\begin{abstract}
The paper shows the effects of two types of long heat treatment at high temperature on copper based alloys with zinc or aluminium.

The resulting increases of transformation temperatures seem to be governed both by loss processes and oxidation of the constitutive elements of the alloy.

Different characterization techniques performed on heat treated samples demonstratethat the surface of the alloy plays an important role during betatization.
\end{abstract}

\section{Introduction}

The transformation temperatures of copper based shape memory alloys are very sensitive to the heat treatment undergone by the sample before training.

Several authors have shown the influence of parameters such as the step quenching, the quenching rate and thermal aging (1) (2) (3).

In this paper we have focussed on the study of the betatization treatment for $\mathrm{Cu}-\mathrm{Zn}-\mathrm{Al}$ and $\mathrm{Cu}-\mathrm{Al}-\mathrm{Ni}$ alloys. It will be shown that the holding time for betatization has a great influence on the transformation temperatures of the material and that surface phenomena are relevant to explain their evolution during the thermal treatment.

\section{1 - Experimental Procedure :}

\section{1 - Samples :}

The chemical composition of the alloys (in weight \%) is given hereafter:

$70.0 \mathrm{Cu}-26.3 \mathrm{Zn}-3.7 \mathrm{Al}$

$83.1 \mathrm{Cu}-12.9 \mathrm{Al}-4.0 \mathrm{Ni}$

$\mathrm{Zr}$ is added in both materials as a refining element, in order to prevent grain growth. The $\mathrm{Cu}-\mathrm{Zn}-\mathrm{Al}$ samples (2 $\mathrm{mm}$ diameter wires) and the $\mathrm{Cu}-\mathrm{Al}-\mathrm{Ni}$ ones $(1.25 \mathrm{~mm}$ diameter wires) exhibit an austenite start temperature (As) of $62^{\circ} \mathrm{C}$ and $158^{\circ} \mathrm{C}$ respectively. The transformation temperatures of shape 
memory alloys are strongly dependent on the composition and can be obtained by empirical expressions (3), (4).

\section{2 - Thermal treatment :}

Two types of thermal treatment have been performed on $\mathrm{Cu}-\mathrm{Zn}-\mathrm{Al}$ and $\mathrm{Cu}-\mathrm{Al}-\mathrm{Ni}$ samples.

The first one is shown on figure 1 . After betatization at $850^{\circ} \mathrm{C}$, the samples are quenched in water at $20^{\circ} \mathrm{C}$ and finally annealed in boilling water for 1 hour (CuZnAl) or in salt bath at $250^{\circ} \mathrm{C}$ for $10 \mathrm{mn}$ (CuAlNi). Different holding times at $850^{\circ} \mathrm{C}$ have been investigated.

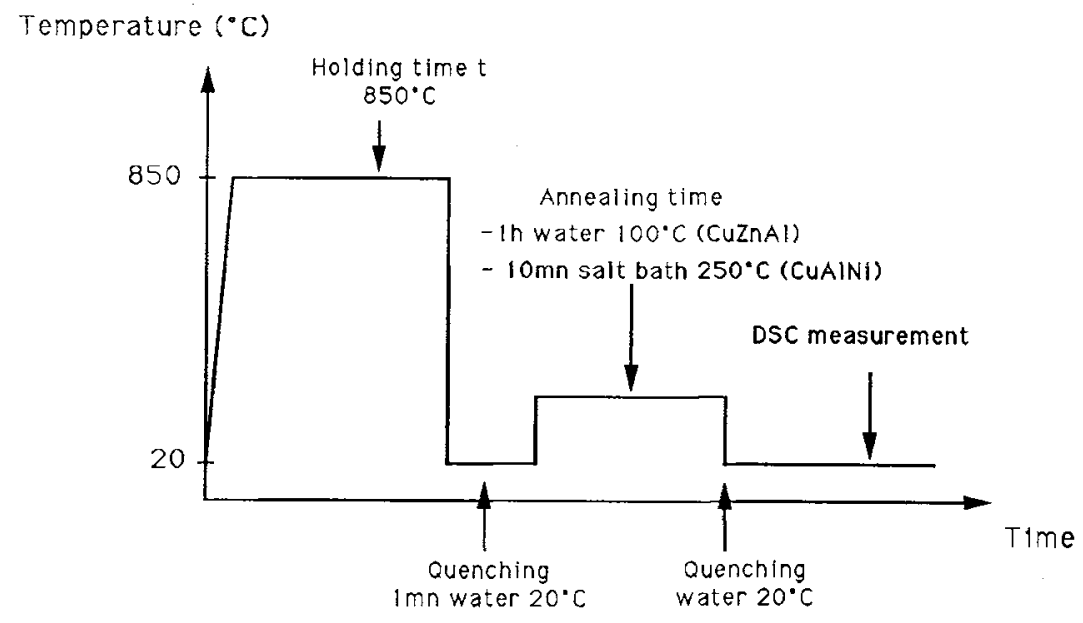

Figure 1 : type of thermal treatment used.

The second heat treatment performed on the samples is shown on figure 2. It is called cumulative heat treatment and will be described in detail in one of the following sections.

Temperature $\left({ }^{\circ} \mathrm{C}\right)$

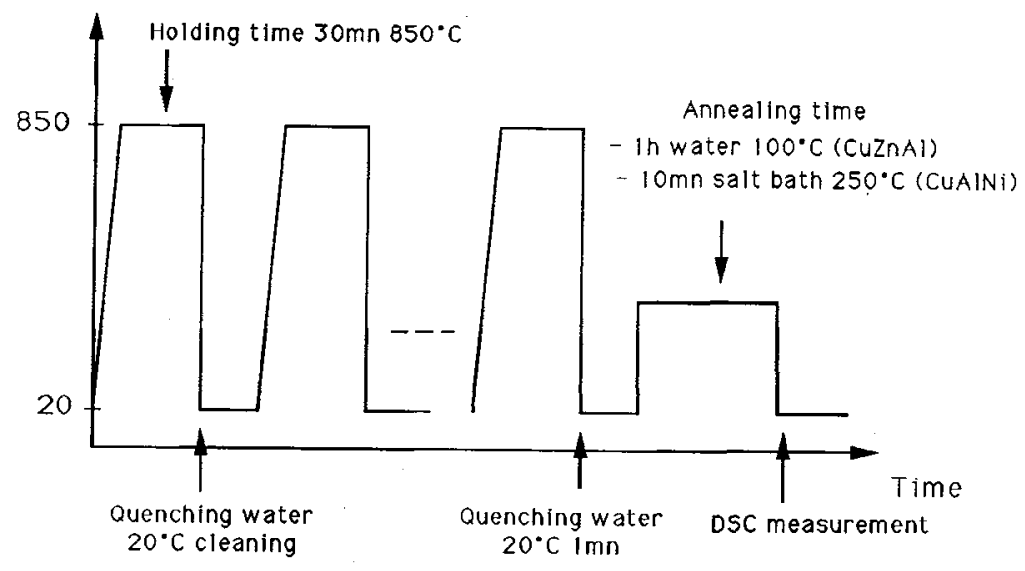

Figure 2 : "Cumulative heat treatment". 
The treatment is a succesion of cycles $\left(30 \mathrm{mn}\right.$ at $850^{\circ} \mathrm{C}$ then quench in water at $\left.20^{\circ} \mathrm{C}\right)$ followed by an annealing treatment specific of the alloy.

The effect of the number of cycles on As will be discussed.

\section{I.3 - Characterization of the sample :}

The annealed samples are quenched in water at $20^{\circ} \mathrm{C}$ before been processed in Differential Scanning Calorimetry experiments for As determination.

The surface of the wires is analysed by Scanning Electron Microscopy, X-ray fluorescence and X-ray diffraction.

\section{II - Results :}

Figures 3 and 4 show the variations of As respectively for Cu-Zn-Al and $\mathrm{Cu}-\mathrm{Al}-\mathrm{Ni}$, as a function of the holding time at $850^{\circ} \mathrm{C}$ for a betatization treatment of the first type.

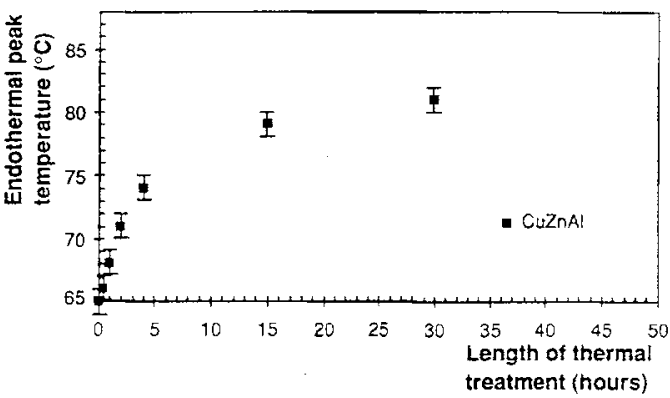

Figure 3 : Transformation temperature as Fig a function of the length of the thermal a treatment. Cu-Zn-Al alloy.

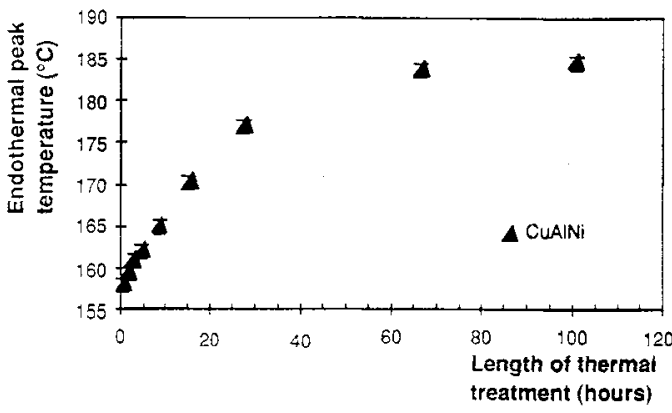

Figure 4 : Transformation temperature as a function of the length of the thermal treatment. Cu-Al-Ni alloy.

It can be seen that As increases and exhibits an asymptotic behaviour for large values of the holding time. The trend is similar for the two alloys.

Micrographic observations of the samples show that no significative grain growth occurs even for prolonged betatization. This confirms the efficiency of $\mathrm{Zr}$ as a refining element.

At the surface of the wire, a coating is revealed by scanning electron microscopy performed on heat treated samples.

This coating is shown on figure 5 for a Cu.Zn.Al alloy heated at $850^{\circ} \mathrm{C}$ for 4 hours and air cooled. The layer does not perfectly coat the sample and is partially separated from its surface.

If the sample is tilted it is possible to measure the thickness $t$ of the coating with a good accuracy. The variations of $t$ with the holding time are reported in table 1. 


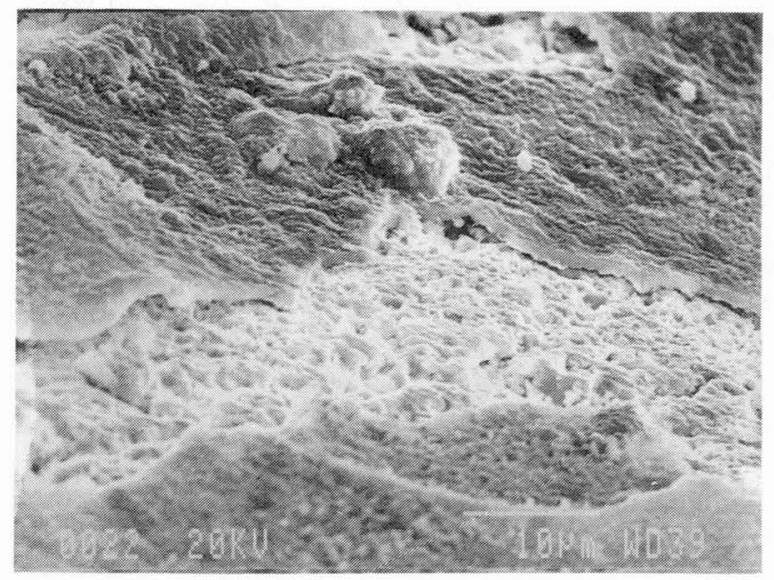

Figure 5 :

\begin{tabular}{|l|c|c|c|c|}
\hline Holding time $(\mathrm{h})$ & 0,25 & 2 & 4 & 8 \\
\hline Thickness $\mathrm{t}(\mathrm{\mu m})$ & 0,60 & 0,85 & 1,10 & 1,10 \\
\hline
\end{tabular}

Table I : Thickness of the layer as a finction of the holding time at $850^{\circ} \mathrm{C}$.

A limiting value of approximately $1.1 \mu \mathrm{m}$ seems to be reached after 4 hours of treatment.

The layer has been characterized both by $X$-ray fluorescence and $X$-ray diffraction.

After beeing heated for 4 hours at $850^{\circ} \mathrm{C}$ and air cooled, the samples were cleaned with alcohol in an ultrasonic bath. The layer is separated from the wire and reduced in powder by the ultrasounds. After alcohol evaporation it is collected for analysis.

$X$-Ray fluorescence ( $\mathrm{Cr}$ tube and $\mathrm{Li} F 200$ crystal) reveals that all the constitutive elements of the material ( $\mathrm{Cu}, \mathrm{Zn}, \mathrm{Al}$, and $\mathrm{Zr}$ ) are present in the coating.

The X-Ray diffraction pattern of the layer is given on fig.6.

Both the number and the width of the reflections make such a pattern difficult to index. However, some possible indexations, corresponding to different oxides of the constitutive elements of the alloy, have been reported on the diagram.

$\mathrm{Cu}_{2} \mathrm{O}$ and $\mathrm{Cu} \mathrm{Al}_{2} \mathrm{O}_{4}$ as well as $\mathrm{Al}_{2} \mathrm{O}_{3}$ are certainly present but no Zinc oxide is detected.

In fact, the structure of the layer is probably much more complex. The wide reflexions attributed to $\mathrm{Al}_{2} \mathrm{O}_{3}$ could correspond to a coordinate Zinc-Aluminium oxide exhibiting more than 50 peaks in the explored angular range. A more detailled investigation is necessary to conclude.

In order to study the importance of the oxide layer on the increase of As during the betetization, the cumulative heat treatment, presented on figure 2 has been untertaken on the two classes of alloys. 


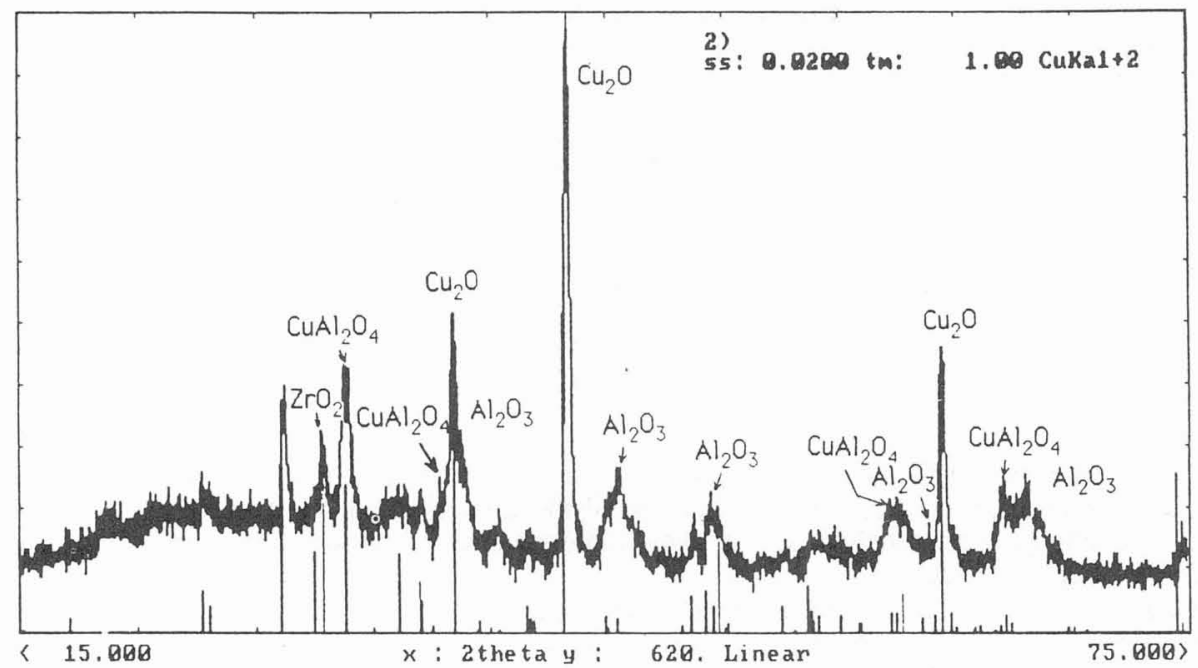

Figure 6 : diffraction pattern of the coating for CuZnAl heat treated alloy.

After each quench in water, the sample is dried and the oxide layer is removed by a light mechanical polishing. A DSC measurement is performed after each cycle and the endothermal peak temperature is plotted against the number of cycles ( Fig.7 and 8).

A linear increase of As is observed for the two classes of alloys but the asymptotic behaviour mentionned for the first treatment is not reached for prolonged treatments, eventhough the total time of betatization is of the same order.

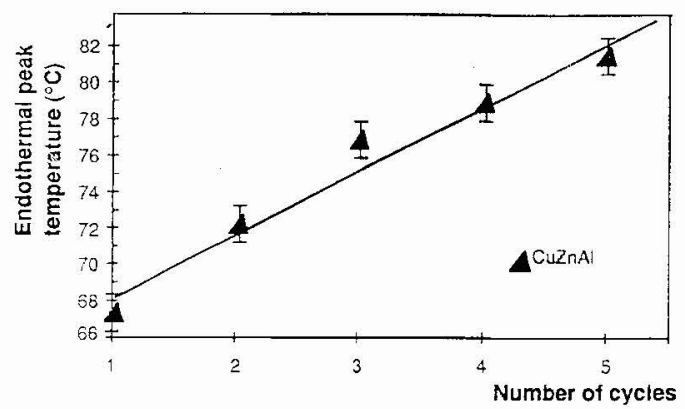

Figure 7 : Transformation temperature as a function of the number of cycles for a cumylative heat treatment on CuZnAl

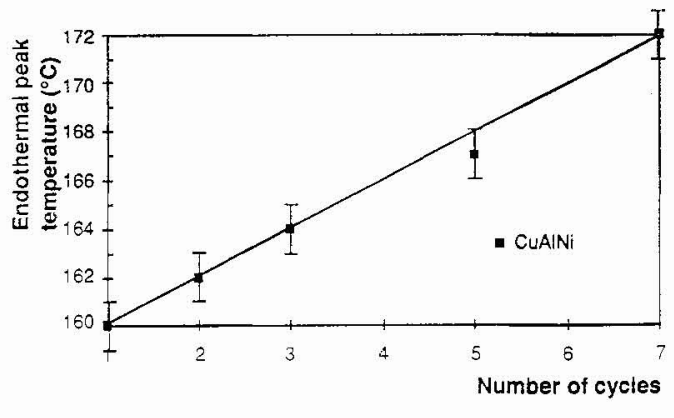

Figure 8 : Transformation temperature as a function of the number of cycles for a cumylative heat treatment on CuAINi 


\section{III - Discussion :}

Controlling the duration of the betatization thermal treatment can be an industrial procedure to reach a suitable transformation temperature for an alloy of given chemical composition.

It has been shown (5) that a loss of Zinc occurs usually for brass heat treated under vacuum. Such a phenomenon is also possible, to a lesser extent, for Cu-Zn-Al heat treated in air, and the increase of As is currently explained by a change of composition of the alloy.

The results presented above (similar behaviour for $\mathrm{Cu}-\mathrm{Zn}-\mathrm{Al}$ and $\mathrm{Cu}-\mathrm{Al}-\mathrm{Ni}$ ), clearly show that the socalled dezincification process, is not only the result of a loss of zinc, as no Zinc is present in the second class of alloy. But, the increase of As is mainly driven by surface phenomena.

As already mentionned (6) (7), oxidation processes seem to be of great importance and are to be taken into account.

A classical betatization heat treatment (without a cleaning of the surface) seems to favour the growth of an oxide coating of complex struclure at the surface of the sample. The composition of this coating is dependant on the chemical composition of the alloy, different oxides such as amorphous and crystalline $\mathrm{Al}_{2} \mathrm{O}_{3}, \mathrm{Cu}_{2} \mathrm{O}, \mathrm{CuAl}_{2} \mathrm{O}_{4}$ are detected.

This layer, whose thickness is a function of the duration of the thermal treatment, leads to a passivation of the surface responsible for a saturation in the variations of As.

It is possible to accelerate the increase of As and, by the way, to master its final value with an appropriate treatment involving a regular removing of the oxide layer formed at the surface of the sample.

\section{REFERENCES :}

(1) R. Rapacioli, M. Alhers, Acta Metallurgica 27 (1979) 777.

(2) S.S. Leu, C.T. Hu, Metallurgical Transactions 22A (1991) 25.

(3) L. Contardo, Thèse n`88 ISAL 0048 (1988).

(4) P. Rodriguez, Thèse $n^{\circ} 89$ ISAL (1989).

(5) T. Shimozaki, H. Shuto, M. Onishi, Transactions of the Japan Institute of Metals 28 (1987) 191.

(6) N. Valverde, Werkstoffe und Korrosion 29 (1978) 644.

(7) S. Beisswenger, Werkstoffe und Korrosion 27 (1976) 159. 